\title{
Drugs and the kidney
}

\section{Analgesic nephropathy}

\author{
ALEXANDER KENNEDY
}

From the Department of Pathology, University of Sheffield Medical School, Sheffield

Analgesic nephropathy has been a source of argument for over 20 years. While the clinical syndrome is now widely recognized and the pathological findings are generally agreed upon the exact pathogenesis and the agents responsible are still a matter of debate. Some authors still regard the association between the use of non-morphine analgesics and renal disease as unproven. Most authorities accept that such an association exists and attribute the aetiology to phenacetin while others regard the role of phenacetin as unproven or exaggerated. This paper attempts to review the features of the syndrome of analgesic nephropathy and its pathology and the main arguments concerning the pathogenesis and aetiology.

\section{The Clinical Syndrome}

The clinical syndrome is now well known and has been described in a number of countries, notably Australia, where it accounts for $17 \%$ of admissions to renal dialysis units (British Medical Journal, 1970) and is the reason for $11.2 \%$ of renal allografts (Kincaid-Smith, Whitworth, Fairley, and Nanra, 1973). The patient is more often a woman than a man and has usually started taking analgesics for migraine or recurrent headaches (Olafson, Gudmansson, and Brekkan, 1966; Gault, Rudwal, and Redmond, 1968). There may have been episodes of urinary infection or attacks of renal colic due to passage of fragments of necrotic papillae but more often the patient presents in a state of renal failure of rapid onset which may have been precipitated by dehydration due to intercurrent illness or surgical operation (Lindeneg, Fischer, Pederman, and Nissen, 1959; Kennedy, 1965; Koutsaimanis and De Wardener, 1970; Lawrence, Disney, and Clarkson, 1973; Lancet, 1973). The history of using analgesics may be difficult to obtain and may be deliberately concealed by the patient until she is faced with the evidence that her own urine contains the metabolites of analgesics (Gault et al, 1968; Dubach, 1970; Murray, Lawson, and Linton, 1971; Murray, 1973a; Murray, 1974). Other drugs may also have been abused and there is frequently a history of alcoholism or other evidenct of an inadequate personality or unfortunate socia circumstances (Murray, 1973b). Patients may have started taking analgesics for some adequate reasofi such as arthritis but often the reason is headache which may be perpetuated by the continued use the drugs and there may be changes in the electroencephalogram (Murray, 1974). In other instances, notably the remarkable situation which existed ff Husqvarna in Sweden, the compounds may be takem with the aim of increasing the capacity for work $\overrightarrow{q r}$ for the aura of well-being which may be induced habituated persons (Grimlund, 1963, 1973).

While the first admission to hospital may be the terminal event substantial improvement may ogeut if the patient is rehydrated, any ureteric obstructiong overcome and any urinary infection treated. If the analgesics can be stopped there may be a gereat improvement in renal function (Hultengren, 196 Bell, Kerr, Swinney, and Yeates, 1969; Kincai $\bar{\Phi}$ Smith, 11970; Kincaid-Smith, Nanra, and Fairles 1970; De Wardener and Koutsaimanis, 197P Lawrence et al, 1973; Lancet, 1973; Kincaid-Smit et al, 1973) for if recognized and adequately treated analgesic nephropathy is a particularly reversibe cause of otherwise fatal renal failure.

Other clinical features include evidence of gastritis, pepticulceration, depression, and anaemia (Dawborn, Fairley, Kincaid-Smith, and King, 1966; Olafson $\underline{\underline{e}}$ al, 1966; Gault et al, 1968; Murray, 1974).

\section{Pathology}

The appearance of the kidneys may vary ve considerably depending upon the stage at which the kidney is examined and on what complications hav occurred. When the pathological picture has not begh obscured by complications such as pyelonephritis qu obstruction, the kidneys may only be slightly res duced in size but the striking feature of the renat cortex is its pallor and tough texture. The generf outline of the kidney may be preserved in early case but usually whole segments of the cortex ate shrunken and this is related to necrosis of the undes 


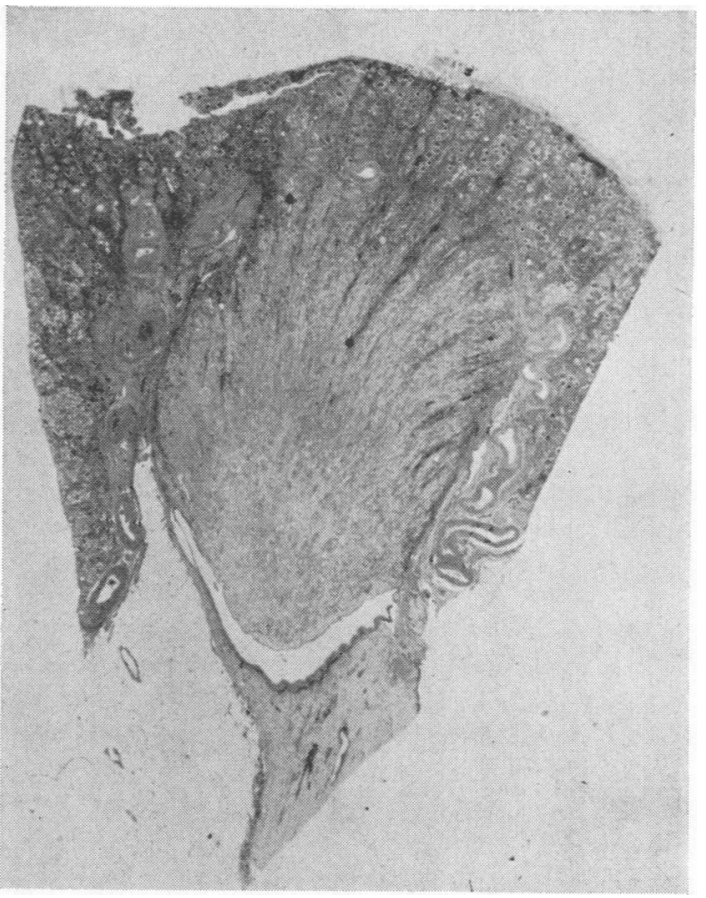

Fig 1 An almost ideal section of the kidney from a case of analgesic nephropathy. The parenchyma is seen in continuity from the capsule to the tip of the papilla. The cortex is contracted and the bulk of the free part of the papilla is necrotic and is devoid of nuclei.

Haematoxylin and eosin $\times 4$.

lying papillae (Sanerkin, 1966; Kincaid-Smith, 1967) (fig 1). The parts of the cortex over normal papillae or over the columns of Bertin may be of comparatively normal texture and thickness and may even be hypertrophied. This relationship between papillary necrosis and cortical shrinkage is only seen when the kidney is sliced but it gives the renal outline a very irregular, knobbly surface. In contrast to the pale cortex, the papillae are usually dark, being described as brown or cyanotic although they may be yellow in cases with recent necrosis (Lindeneg et al, 1959; Sanerkin, 1966; Burry, 1966, 1968, 1970). There may be partial calcification of the papillae, they may be lying loose in the pelvic cavity, or they may be missing altogether in advanced cases. There may be some thickening of the pelvic wall but unless there is obstruction or secondary pyelonephritis the pelvis and ureter are usually of normal size.

In more advanced cases renal shrinkage is much more evident and the kidneys may weigh as little as $40 \mathrm{~g}$ each. The thinning of the cortex is more generalized but the relationship of the shrunken areas to the necrotic papillae is usually still evident.

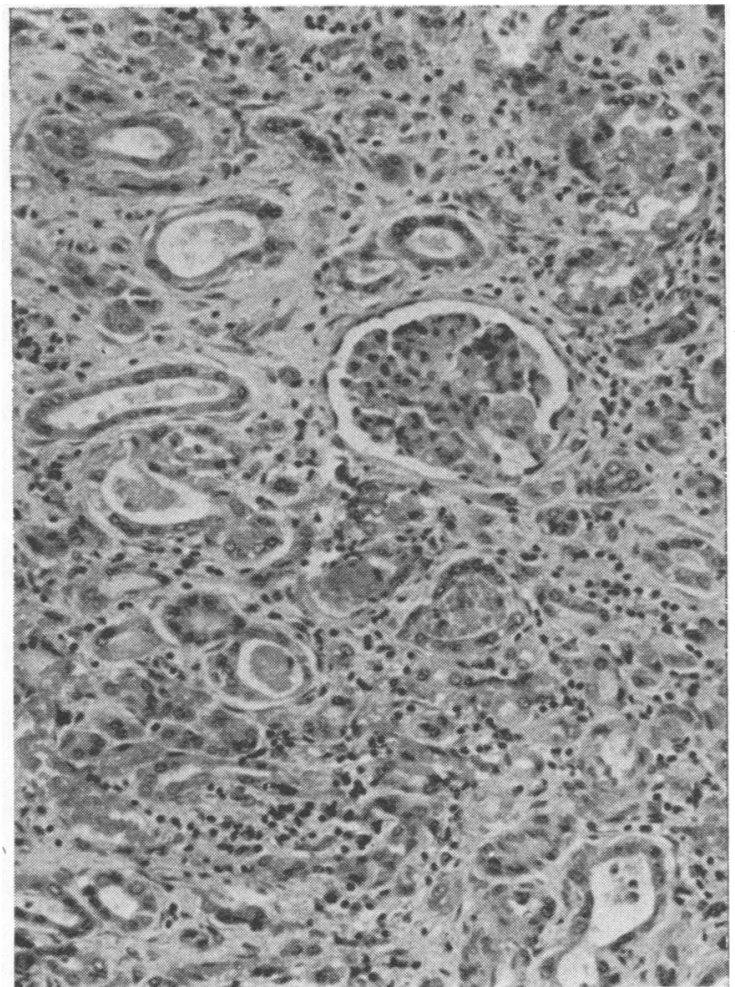

Fig 2 The renal cortex overlying and draining through a necrotic papilla. The glomerulus is relatively normal but there are shrinkage and loss of tubules. There is an increase in connective tissue with a diffuse lymphocytic infiltrate. $H \& E \times 170$.

The histological changes in the cortex are mainly those of loss of nephrons with diffuse replacement fibrosis thus giving the cortex its pallor and tough texture (fig 2). Unless infection has supervened much of the cortex may consist of normal-looking nephrons set in fibrous tissue with a patchy infiltrate consisting of a few lymphocytes and collections of small tubules which are undergoing atrophy. The glomeruli usually show little abnormality but some of the atrophied tubules usually contain brown iron-free crystalline material with the staining characteristics of lipofuscin (Gloor, 1965). Staining of the basement membranes of the tubules by the PAS technique often shows that they are thickened and reduplicated, especially those of the nephrons which are undergoing atrophy (fig 3). Despite the severity of the changes in the affected areas of the cortex, the intervening areas may appear unremarkable and show nothing more than the pathological features usual for the patient's age. 


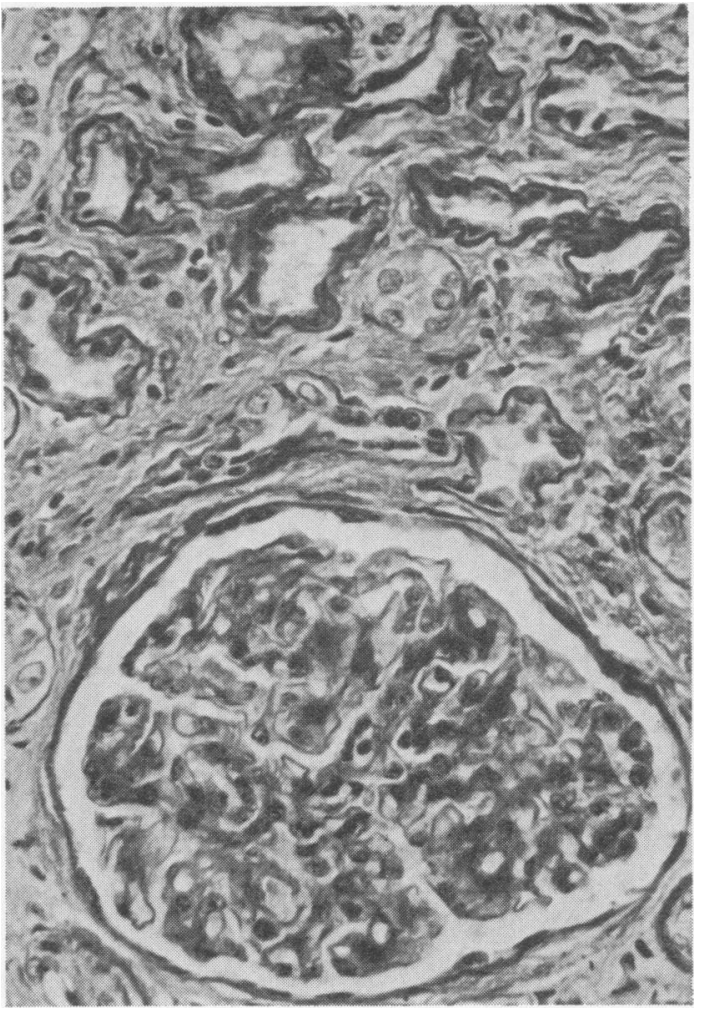

Fig 3

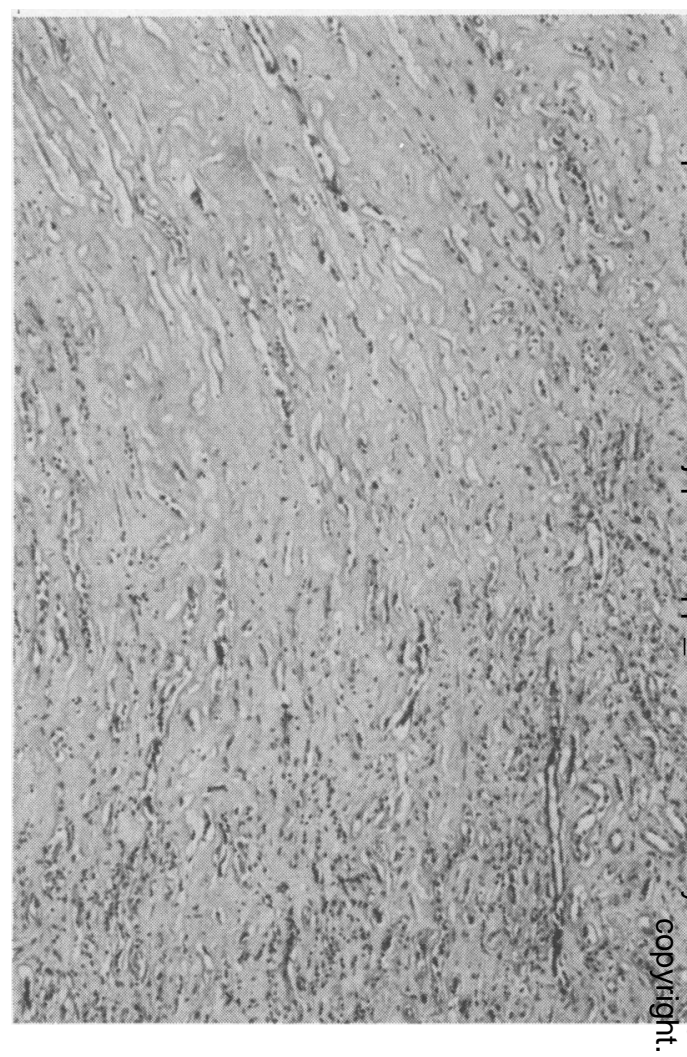

Fig 4

Fig 3 A contracted area of the cortex in which there is gross thickening of the basement membrane of the tubules which are separated by fibrous tissue. PAS $\times 422$.

Fig 4 Papillary necrosis of Schourup's type II. This is a bland necrosis without a clearly demarcated border and with little inflammatory infiltrate. The necrotic area merges gradually with the viable stump of the medulla. $H \& E \times 64$.

As the medulla is entered the number of tubules visible diminishes markedly and many may be choked with debris. In the papilla the outlines of the tubules may be preserved but the surface is denuded of any covering epithelium. At the tip of the papilla, all the tubules may appear like this but the extent and the margin of the necrotic zone are variable. In the cases in which the necrosis has developed slowly without infection or episodes of circulatory failure, the necrotic area merges gradually with the viable stump of the medulla with no clear line of demarcation (fig 4), unlike that found in the more acute forms of renal papillary necrosis induced by such events as urinary obstruction (Schourup, 1957; Davies, Kennedy, and Roberts, 1970). However, the form taken by the necrosis is not constant, and, while an ill defined area, ie, Schourup's type II, is usual, more clearly demarcated lesions (type I) maq be found, especially in cases where renal function has failed abruptly. Thus, no one type of necrosis specific (Burry, 1970; Davies et al, 1970).

In the more advanced cases in which there has been severe shrinkage of the cortex other more non specific changes are common. The lymphocytie infiltrate is often heavier, more fibrosis is pres sent, and there are sometimes deposits of calciunf oxalate crystals (Scheidegger, 1958). The otherf change which may be seen in the later stages is the presence of vascular lesions of the type seen in hypero tension. These are usually only a late manifestatio (Burry, 1968), and these changes are probably more related to the state of the patient's cardiovasculase system than being in any way specific to analgesio nephropathy. 
The Pathological Diagnosis of Analgesic Nephropathy

When the pathologist is faced with an irregularly shrunken pale kidney with necrotic papillae from a patient who is known to have used large quantities of analgesics the diagnosis is obvious. In spite of this, the frequency of recognition in different countries has varied considerably, and a retrospective study by pathologists who are specially interested in the condition may reveal few cases (Davies et al, 1970). There are several reasons for this of which the first is the reliability of the history of the drugs taken. While such a history must always be sought, many of these patients are seen in a state of terminal renal failure and an accurate history may not be available because of the state of the patient's health at the time of admission to hospital. Secondly, as already mentioned, the true state of affairs may have been deliberately concealed by the patient, and lastly there are reasons associated with the pathologist's approach to the problem.

The characteristic feature of analgesic nephropathy is the presence of renal papillary necrosis but this may have a number of causes other than drug abuse, notably urinary obstruction, diabetes, renal vein thrombosis, and pyelonephritis (Schourup, 1957; Jacobs and Morris, 1962; Bengtsson, 1962; Harvald, 1963; Burry, de Jersey, and Weedon, 1966; Davies et al, 1970). The cautious pathologist is usually unwilling to attribute a lesion to the effect of a drug when there is some natural explanation available. Thus renal papillary necrosis in a patient with prostatic hyperplasia is more likely to be regarded as due to urinary obstruction than due to analgesics, especially if the history of abuse has been suppressed. Furthermore kidneys which have been damaged by analgesics in the first instance may become secondarily infected so that the presentation is one of renal failure and pyelonephritis. Although there are differences between analgesic nephropathy and chronic pyelonephritis (Bengtsson, 1962), under these circumstances the renal failure may be attributed to infection rather than to the underlying drug-induced nephropathy. Finally, in a small, shrunken kidney with superimposed infection or arterial changes good evidence of the preceding disease process may be difficult to recognize, especially if the papillae have disappeared altogether.

All these factors may have led to the underdiagnosis of analgesic nephropathy in areas where, unlike Scandinavia, Switzerland, and Australia, the condition has not achieved much prominence. Even so there are probably genuine differences in incidence between the countries concerned. When renal papillary necrosis is present there are two pieces of information which may indicate that the necrosis is due to analgesics: these are the history and the nature of the necrosis.

In the absence of a reliable drug history there may be other suggestive features of the syndrome such as mental irritability, anaemia, peptic ulceration, a history of migraine, or dependence on other drugs. There may be some valid reason for using large quantities of drugs such as the presence of rheumatoid arthritis and many instances of analgesic nephropathy have been found amongst such patients (Clausen and Pedersen, 1961; Lancet, 1966: Lawson and McLean, 1966). The quantity of drugs taken is significant and the possibility of analgesic nephropathy should be considered whenever there is a history of the regular consumption of six or more doses per day over more than two years. Unfortunately the doses involved have often been recorded in terms of the phenacetin content and this has varied from a cumulated dose of 1 or 2 kilogrammes to over 15 kilogrammes or more (Rubenstein, Abraham, Stables, and Levin, 1968). Most patients with analgesicnephropathy have taken, in terms of phenacetin, a dose of at least $1 \mathrm{~g}$ per day for three years or more with a total dose of over $3 \mathrm{~kg}$ (Buchanan, 1961; Murray, 1972).

The nature of the necrosis gives some indication as to the possibility of drugs being implicated. Different variants of papillary necrosis have been described (Schourup, 1957; Davies et al, 1970). These fall into two types: acute infarct-like lesions and bland ill-defined areas of necrosis which merge gradually with the viable stump of the medulla. Both types occur in analgesic nephropathy (KincaidSmith, 1967) but where there is segmental thinning of the cortex over clearly necrotic papilla with necrosis of the bland type (Schourup type II) the diagnosis of analgesic nephropathy is highly probable.

These remarks indicate that a sine qua non for the identification of the renal changes is that adequate histological material must be available. The blocks taken must include the whole of the papilla down to the tip and the overlying cortex which drains through that particular papilla (fig 1). To obtain a block of this sort requires very special care and, as suggested by Kincaid-Smith, it is sometimes helpful to slice the kidney transversely (Kincaid-Smith, 1967). Conventionally selected material often includes no papilla at all or else a papilla which has no relationship with the cortex present in the specimen. However, with care, adequate blocks can be obtained from kidneys which have been sliced longitudinally in the usual way.

\section{Pathogenesis}

The changes in the kidney in the analgesic abuse 
syndrome were at first described as chronic interstitial nephritis (Spühler and Zollinger, 1953). It was only later that it was realized that the cortical changes are of secondary importance when Sanerkin (1966) drew attention to the anatomical relationship between the necrotic papillae and the areas of shrinkage in the cortex and concluded that the cortical contraction was a direct result of the damage occurring in the medulla. The involvement of the vasa recta and Henle's loops must inevitably have some effect on the overlying cortex, and the sparing of the columns of Bertin (fig 1) can be attributed to the fact that the collecting ducts from these areas drain into the lateral, and basal, portions of the papillae and so may be preserved (Kincaid-Smith, 1967). Evidence that the primary event is in the papilla and not in the cortex is provided by the fact that necrosis of the papilla occurs before shrinkage of the cortex (Burry et al, 1966; Dawborn et al, 1966; Axelsen and Burry, 1973). Furthermore renal biopsy has provided further evidence that the initial changes are medullary (Gault and Muehrke, 1973).

There is now experimental support for this hypothesis. A variety of experiments have been devised in which the renal papillae of experimental animals have been destroyed by drugs or by surgery (Davies, 1968; Lucke, Messervy, Lucke, and Hunt, 1968; Ham and Tange, 1969; Swales, Funder, and Tange, 1973). Cortical atrophy does not seem to be an invariable result of this procedure but in most experiments of this sort shrinkage and fibrosis of the cortex does occur (Davies, 1969; Lucke et al, 1968). In Davies' experiments, in which the medulla was destroyed by using ethyleneimine, the cortical changes consisted of tubular atrophy, fibrosis, chronic inflammatory cell infiltration, and deposits of lipofuscin. All these changes are similar to those seen in the shrunken area of the cortex in human cases of analgesic nephropathy but they are probably non-specific, as far as analgesics are concerned, and represent the reaction of the cortex to obstruction of the collecting ducts, loops of Henle, and the vessels of the medulla.

Further evidence is provided by those animal experiments in which large doses of analgesics have been administered in an attempt to reproduce analgesic nephritis experimentally. The relevance of these experiments to human disease will be discussed but it is significant that in those which have been successful, in that the anatomical changes have been induced, the initial lesion has been in the papilla without necessarily producing cortical changes until later (Abrahams, Rubenstein, and Levin, 1963; Abrahams, Rubenstein, Levin, and Wunderlich, 1964; Fordham, Huffines, and Welt, 1965; Abrahams and Levin, 1968; Brown and Hardy,
1968; Kincaid-Smith, Saker, and McKenzie, 1968 Kincaid-Smith, Saker, McKenzie, and Murieen, 1968b; Nanra, Chirawong, and Kincaid-Smith, 1973). The concept of renal papillary necrosis being the initial event accounts admirably for the irregü cortical contraction seen in man but what is fess clear is whether the action of the drugs on the medulla is due to a toxic effect on the epithelial cells or to a primary vascular event causing medulghry ischaemia.

A further factor is the role of infection which in may certainly complicate and obscure the usual pa logical picture. Some experiments have been designed to show whether infection plays any parfin the pathogenesis of the lesion. The results in तुhe main have been unconvincing or completely negative and the fact remains that analgesic nephropathy can occur in patients with no evidence of infecton at all. Furthermore in one population study gvidence of urinary infection was no more frequent in the analgesic takers than in the remainder (Dubach, Levy, and Müller, 1971).

\section{Aetiology}

In reviewing the various views of the aetiolog analgesic nephropathy three general opinions Ean be detected. First there are some who seem to regard the whole subject as suspect and who claim that the connexion between renal disease and analgesics is still unproven. Secondly there are those who fegard phenacetin as the main agent responsible, what Gne might call the European school of thought. Laकtly there are those who regard the case against phenacetin as, at best, unproven and consider that $\mathbb{R}^{\circ}$ is the drugs taken with phenacetin, notably asp:Bin, which are really responsible. These points of view will now be considered in turn.

There have been a number of studies in whin selected populations, often of patients with arthris, have been screened for the presence of renal dise and the findings compared with the histories of $\exists^{\prime}$ drug usage. Sørensen $(1965,1966)$, Schreiner (1963), and Gilman (1965) reviewed the available evidence but remained sceptical about the validity of the case against analgesics. Schreiner $(1965,1966)$ foundsno relationship between the drug dosage and The glomerular filtration rate, as measured by creatianne clearance, in studies of patients with and withojut rheumatoid arthritis. Lawson (1973), reporting on the results of the Boston Collaborative Dfug Surveillance Program, also found no firm evidénce that analgesic users had more renal diseaser as measured by the blood urea levels, urine anaksis, and diagnosis on discharge. Waters, Elwood, 角d Asscher (1973) found that although analgesic takers 
had more urinary symptoms their plasma urea and creatinine levels, blood pressure, and urinary concentrating power did not deteriorate. Similarly the results of a New Zealand Rheumatism Association Study (1974) did not show a clear relationship between renal changes and dosage. Unfortunately many studies of this sort have a number of defects. First, as pointed out by Davies (1966), the primary lesion in analgesic nephropathy is in the papilla so that the first function test which is likely to be altered is the concentrating power; measurements of the creatinine clearance and blood urea are much less sensitive detectors of early renal impairment. Secondly, patients with analgesic nephropathy may be regarded as liars as far as their drug usage is concerned (Gault et al, 1968; Murray, 1973a, 1974) and it is essential to test the urine for drug metabolites before accepting the patient's story. Where this has been done a relationship between drug usage and renal impairment has been found (Lancet, 1973; Dubach $e t$ al, 1971) and the very strong epidemiological evidence from Sweden (Nordenfeldt and Ringertz, 1961; Grimlund, 1963, 1965, 1973; Bengtsson and Hood, 1965) is difficult to ignore. It may also be argued that patients with rheumatoid arthritis are different from analgesic addicts in that they take their drugs under medical supervision for a real rather than a half-imagined disability. They are, therefore, less likely to achieve the enormous intake of the person who is habituated to analgesics due to a conviction that the tablets are in some way beneficial or provide some stimulatory effect. Studies of patients with rheumatoid arthritis are also influenced by the fact that the arthritis itself may have some deleterious effect on renal function and that the drug history may be long and complex.

One conclusion which can be drawn from these studies is that analgesic usage is common in the population and that many people may take considerable quantities of analgesics without coming to serious harm. This is a valuable contribution in that a drug as useful as aspirin need not be denied to those who really need it.

The second main body of opinion has laid the blame at the door of phenacetin. A popular argument has been the common denominator theory which argues that as phenacetin is rarely abused alone but is the common factor in a number of compound medicaments which have been blamed, such as aspirin, phenacetin and codeine, aspirin, phenacetin and caffeine, phenazone, phenacetin and caffeine (Hjortons powder, Grimlund, 1963), phenacetin, caffeine, and amidopyrine, and Persedon and other combinations. The weakness of this argument has been neatly exposed by Gilman (1964). Prescott $(1970 \mathrm{a}$ and $\mathrm{b})$ also has argued that the common pre- sence of phenacetin in the combinations taken by analgesic addicts does not exonerate from blame the other drugs which are present and which are known to have effects on the kidney. Furthermore it is exceedingly difficult to produce renal lesions in rats using phenacetin alone and the doses used have often been so large as to prove little but the fact that, in rats, phenacetin is a remarkably safe drug (Gilman, 1965).

While much of the experimental work, reviewed below, indicates that it is aspirin and not phenacetin which is most harmful for the kidney, there is very strong epidemiological evidence for the central role of phenacetin. The most remarkable evidence comes from the town of Husqvarna in Sweden where, due to unusual historical and industrial reasons described by Grimlund (1963), there was widespread abuse of a combination of phenazone, phenacetin, and caffeine by men. While most series of cases of analgesic nephropathy have mainly had an excess of women, in Husqvarna the excess deaths from renal disease were among men and did not affect nearby Swedish towns. Even more significant is the fact that following limitations in the sale of phenacetin in 1961 the number of cases of renal disease began to show a fall within a few years (Bengtsson, 1969; Nordenfeldt, 1972; Grimlund, 1973) even though the use of the other drugs, phenazone and caffeine, has increased rather than declined. There is a suggestion that this pattern of a reduction in the number of cases following limitation of the sale of phenacetin may also have occurred in Australia (Axelsen and Burry, 1973) and it now remains to be seen whether the limitations imposed in Britain in the autumn of 1974 will have a similar effect. These changes of incidence represent exceedingly strong evidence that phenacetin is harmful.

Australian workers and others, notably Prescott (1970a and b), have emphasized the important role of the drugs which are used in combination with phenacetin and, in particular, the role of aspirin. While the evidence against phenacetin largely depends on epidemiology in man, that against aspirin is largely of experimental origin.

As already mentioned, experimental renal papillary necrosis in the rat is much more readily produced by aspirin than by phenacetin (Saker and Kincaid-Smith, 1969; Nanra, Chirawong, and Kincaid-Smith, 1970; Nanra and Kincaid-Smith, 1970, 1973a and b). Combinations of aspirin and phenacetin appear to be more toxic than phenacetin alone and the toxicity is enhanced by dehydration of the animals while a water diuresis is to some extent protective (Kincaid-Smith et al, 1968; Saker and Kincaid-Smith, 1969; Nanra and Kincaid-Smith, $1970,1973 a$ and $b$ ). Furthermore the same group of 


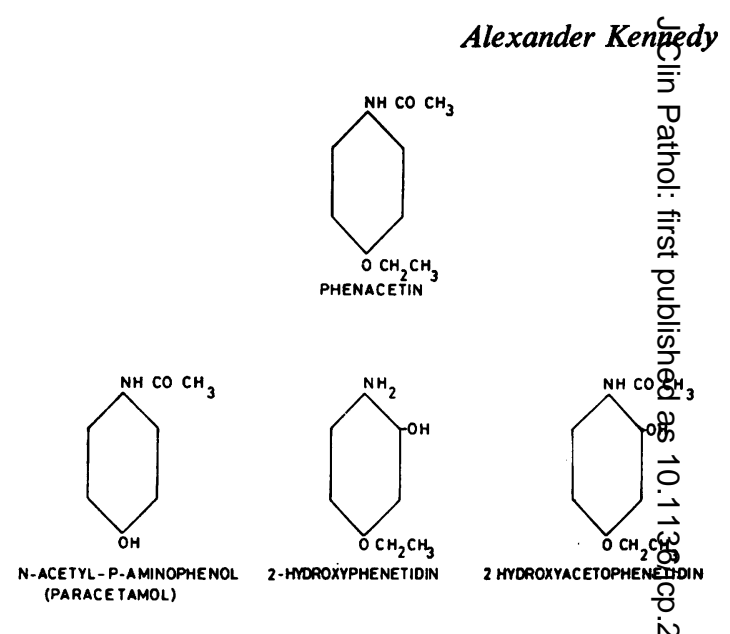

workers have found no evidence that 4-chloroacetanilide, a minor contaminant of phenacetin, is responsible. The effect of dehydration is in accordance with the clinical observation that patients with analgesic nephropathy can deteriorate rapidly due to intercurrent illness or surgical operation.

Aspirin in adequate doses is certainly toxic for the proximal tubules in the cortex and may cause acute tubular necrosis (Campbell and McClaurin, 1958; Robinson, Nicholls, and Taitz, 1967) but this may be irrelevant as the primary lesion in analgesic nephropathy is in the medulla. It has been found that even therapeutic doses of aspirin induce an increased excretion of epithelial cells in the urine and this has been regarded as evidence that aspirin is not only nephrotoxic but more toxic than phenacetin (Harvald, Valorf-Hensen, and Nielsen, 1960; Scott, Denman, and Dorling, 1963; Prescott, 1969, 1970). The importance of these data has been greatly overemphasized because the number of cells excreted after a dose of a drug is dependent not only on its toxicity but on its site of action. Agents which, like aspirin, affect the cortex cause a much greater excretion of cells than those affecting the medulla. In rats fatal medullary lesions may cause less celluria than minor recoverable necrosis in the cortex (Davies and Kennedy, 1967a and b; Davies, Kennedy, and Roberts, 1969; Davies, Kennedy, and Saluga, 1968). Thus the failure of phenacetin to induce a large increase in cell output in man (Prescott, 1965) does not prove that it is less harmful than aspirin. Furthermore the cells excreted in response to aspirin are probably derived from the proximal tubule (Kennedy and Saluga, 1970), a site of action where nephrotoxic agents produce the greatest celluria but which is not the primary site of damage in analgesic nephropathy.

The final piece of evidence to consider is the effect of withdrawing the drugs from patients with analgesic nephropathy. Again there is some disagreement on the necessity of withdrawing all analgesics. Kincaid-Smith and her colleagues have stated that it is essential for the patients to avoid all drugs of this group including aspirin (Kincaid-Smith, 1970). Other experience indicates that recovery may take place even if the use of aspirin is continued provided phenacetin is avoided (De Wardener and Koutsaimanis, 1971). The number of contradictions between the Australian and European experience suggest that some other factor, such as higher climatic temperatures, may play a part in the frequency and severity of the disease seen in Australia.

While the main debate has been concerned with the relative dangers of phenacetin and aspirin there have been occasional cases reported in which renal

Fig 5 Phenacetin and three of its metabolites. The bulk of ingested phenacetin is rapidly converted into $N$-acetyl paraminophenol. Small quantities of 2-hydroxylated compounds are produced and it is compounds such as these which could be responsible $f \circ$ the development of urothelial tumours.

Figures 2, 3, and 4 are reproduced by permission of the Editor of the Journal of Pathology.

papillary necrosis has been attributed to as abuse or other drugs, notably paracetamol (Preseott, 1966, 1969; Krikler, 1967; Kincaid-Smith, 1969 ; Kerr, 1970). However, one of Kerr's patiend gllso took phenacetin, and aspirin was not a comgonent of Hjorton's powder which was responsible topthe deaths in Husqvarna. Deaths due to chronic abuse of aspirin are very much less frequent than those associated with phenacetin combinations. Pagacetamol, or $\mathrm{N}$-acetyl paraminophenol (fig 5), is $9 e r-$ haps important because it is the main metabolite of phenacetin in man so that if phenacetin is suspect, paracetamol also must be regarded as dangerous

In conclusion it may be said that more deaths have been regarded as being associated with phenacetin than with aspirin and that phenacetin is more likely than aspirin to cause habituation. The deletion of phenacetin from proprietary tablets and powders would not be a serious loss; there seens to be a prima facie case for limiting its use and where such limitation has already been imposed the regults seem favourable. Despite the experimental fevidence, observations on man suggest that aspirm is reasonably safe when taken in moderation andthe risks involved in the use of aspirin must be weighed against its usefulness.

\section{Neoplasia and Analgesic Nephropathy}

One final association of excessive analgesic cons tion which has been reported in recent years is with 
urothelial cancers (Bengtsson, Angervall, Ekman, and Lehmann, 1968; Bengtsson, 1969; Lancet, 1969; Angervall, Bengtsson, Zetterlund, and Zsigmond, 1969; Bengtsson and Angervall, 1970; Bengtsson, Angervall, Johannson, and Wolquist, 1973; Høybe and Nielsen, 1973; Marrion and Susmano, 1973; Zetterlund, 1973). The association has been noted mainly in Europe to date and is based on the high incidence of urothelial tumours in patients who are followed after a diagnosis of analgesic nephropathy. The authors who have reported this association have not found the same incidence in patients with chronic pyelonephritis in association with analgesic abuse. The tumours have had a high incidence in Husqvarna (Høybe and Nielsen, 1973; Zetterlund, 1973), and, although urothelial cancer is normally a tumour which predominantly affects males, among analgesic abusers, who are largely female, the sex ratio is reversed (Angervall et al, 1969). The tumours have been transitional cell or anaplastic and in some instances recurrent or multiple.

A possible explanation for this association lies in the metabolism of phenacetin, a small proportion of which is converted to 2-hydroxy-acetophenetidin and 2-hydroxyphenetedin (fig 5). It is known from studies of aniline dyes that the metabolites that are carcinogenic are orthohydroxyamines (Clayson, 1962) and it may be significant that phenacetin also may give rise to orthohydroxylated metabolites (Angervall et al, 1969). The position is further complicated by the fact that there is interaction between cigarette smoking and the metabolism of phenacetin although, curiously enough, non-smokers excrete more 2-hydroxylated derivatives than do smokers (Welch and Gillespie, 1973).

It may be that significant numbers of analgesic abusers are attending urological clinics for the treatment of tumours and that perhaps patients attending urological clinics should be reviewed for analgesic abuse by testing their urine for metabolites. A further consideration is that now it is possible for patients with analgesic nephropathy to survive with energetic treatment more such addicts may survive to develop tumours.

\section{Conclusions}

There seems to be good evidence that people who habitually take more than five or six doses per day of the common analgesics run a significant risk of developing renal disease. This takes the form of renal papillary necrosis which leads to contraction and fibrosis of the overlying segments of the cortex. The pathological picture may be obscured by sloughing of the papilla or by secondary infection.
The history of drug taking is often concealed by the patient and where the renal pathology is complicated by other causes of renal disease, particularly obstruction and infection, the true nature of the condition may go unrecognized by clinician and pathologist alike. Dehydration appears to increase the susceptibility of the kidney to damage by the drugs responsible and may precipitate acute renal failure. Other clinical features include anaemia, peptic ulceration, or a history of persistent headaches and psychological abnormalities.

The evidence as to which drugs are responsible is conflicting. The case against phenacetin is not completely proven but aspirin-phenacetin combinations seem to be particularly dangerous. Despite the experimental evidence incriminating aspirin the clinical evidence suggests that most people can take it in moderation without harm. The limitations recently imposed on the use of phenacetin can do little harm and the evidence to date suggests that such limitations could be of great benefit. It may be that as the years pass we shall find that the problem of analgesic nephropathy has begun to disappear and much will have been achieved. Should this view be mistaken little will have been lost provided we do not become blind to the nephrotoxic potential of other drugs such as aspirin.

References

Abrahams, C., and Levin, N. W. (1968). Analgesic nephropathy. Lancet, 1, 645.

Abrahams, C., Rubenstein, A. H., and Levin, N. W. (1963). Phenacetin-induced papillary damage in experimental animals. Nature (Lond.), 200, 695-696.

Abrahams, C., Rubenstein, A. H., Levin, N. W., and Wunderlich, U. (1964). Experimentally induced analgesic nephritis in rats. Arch. Path., 78, 222-230.

Angervall, L., Bengtsson, U., Zetterlund, C. G., and Zsigmond, M. (1969). Renal pelvic carcinoma in a Swedish district with abuse of a phenacetin-containing drug. Brit. J. Urol., 41, 401-405.

Axelsen, R. A., and Burry, A. F. (1973). Analgesics and the kidney. Brit. med. J., 4, 784-785.

Bell, D., Kerr, D. N. S., Swinney, J., and Yeates, W. K. (1969). Analgesic nephropathy: clinical course after withdrawal of phenacetin. Brit. med. J., 3, 378-382.

Bengtsson, U. (1962). A comparative study of chronic non-obstructive pyelonephritis and renal papillary necrosis. Acta med. scand., Suppl., 388.

Bengtsson, U. (1969). Phenacetin. Lancet, 1, 264-5.

Bengtsson, U., and Angervall, L. (1970). Analgesic abuse and tumours of renal pelvis. (Letter) Lancet, 1, 305.

Bengtsson, U., Angervall, L., Ekman, H., and Lehmann, L. (1968). Transitional cell tumors of the renal pelvis in analgesic abusers. Scand. J. Urol. Nephrol., 2, 145-150.

Bengtsson, U., Angervall, L., Johansson, S., and Wolquist, L. (1973). Phenacetin abuse and renal pelvic carcinoma. In Problems of Phenacetin Abuse, edited by H. Haschek, pp. 221-226. Egermann, Vienna.

Bengtsson, U., and Hood, B. (1965). Abuse of phenacetin-containing analgesics and renal damage. In Progress in Pyelonephritis, edited by E. H. Kass. Davis, Philadelphia.

British Medical Journal (1970). Analgesic nephropathy. (Leading article) Brit. med. J., 4, 125-126.

Brown, D. M., and Hardy, T. L. (1968). Short term study of the effect 
of phenacetin, phenazone and amidopyrine on the rat kidney. Brit. J. Pharmacol., 32, 17-24.

Buchanan, J. G. (1961). Phenacetin induced chronic interstitial nephritis. N.Z. med. J., 60, 207-208.

Burry, A. F. (1966). A profile of renal disease in Queensland: results of an autopsy survey. Med.J. Aust., 1, 826-834.

Burry, A. F. (1968). The evaluation of analgesic nephropathy. Nephron, 5, 185-201.

Burry, A. F. (1970). The pathology and pathogenesis of renal papillary necrosis. In Renal Infection and Renal Scarring, edited by P. Kincaid Smith and K. F. Fairley, pp. 335-344. Mercedes, Melbourne.

Burry, A. F., de Jersey, P., and Weedon, D. (1966). Phenacetin and renal papillary necrosis: results of a prospective autopsy investigation. Med. J. Aust., 1, 873-879.

Campbell, E. J. M., and McClaurin, R. E. (1958). Acute renal failure in salicylate poisoning. Brit. med. J., 1, 503-505.

Clausen, E., and Pedersen, J. (1961). Necrosis of the renal papillae in rheumatoid arthritis. Acta med. scand., 170, 631-633.

Clayson, D. B. (1962). Chemical Carcinogenesis. Churchill, London.

Davies, D. J. (1966). Discussion on the paper of Prescott. J. Pharm. Pharmacol., 18, 351-352.

Davies, D. J. (1968). Changes in the renal cortex following experimental medullary necrosis. Arch. Path., 86, 377-382.

Davies, D. J., and Kennedy, A. (1967a). The excretion of renal cells following necrosis of the proximal convoluted tubule. Brit. J. exp. Path., 48, 45-50.

Davies, D. J., and Kennedy, A. (1967b). Course of the renal excretion of cells after necrosis of the proximal convoluted tubule by mərcuric chloride. Toxicol. appl. pharmacol., 10, 62-68.

Davies, D. J., Kennedy, A., and Roberts, C. (1969). The excretion of renal cells following necrosis of the distal segment of the nephron by hexadimethrine bromide. Brit. J. exp. Path., 50, 319-326.

Davies, D. J., Kennedy, A., and Roberts, C. (1970). The aetiology of renal medullary necrosis: a survey of adult cases in Liverpool. J. Path., 100, 257-268.

Davies, D. J., Kennedy, A., and Saluga, P. G. (1968). Significance of the urinary excretion of cells after experimental medullary necrosis. Ann. rheum. Dis., 27, 130-136.

Dawborn, J. K., Fairley, K. F., Kincaid Smith, P., and King, W. E. (1966). The association of peptic ulceration, chronic renal disease and analgesic abuse. Quart. J. Med., 35, 69-83.

De Wardener, H. E., and Koutsaimanis, K. G. (1971). Phenacetin nephropathy. Brit. med. J., 2, 45-46.

Dubach, U. C. (1970). Analgesic nephropathy. Brit. med. J., 4, 618619.

Dubach, U. C., Levy, P. S., and Müller, A. (1971). Relationships between regular analgesic intake and urorenal disorders in a working female population of Switzerland. I. Initial results. Amer. J. Epidem., 93, 425-434.

Fordham, C. C., III, Huffines, W. D., and Welt, L. G. (1965). Phenacetin induced renal lesion in the rat. In Progress in Pyelonephritis, edited by E. H. Kass, pp. 325-331. Davis, Philadelphia.

Fordham, C. D., III, Huffines, W.D., and Welt, L. G. (1969). Phenacetin induced renal disease in rats. Ann. intern. Med., 62, 738-743.

Gault, M. H., and Muehrcke, R. C. (1973). Some clinical-pathological correlations in patients with analgesic nephropathy. In Problems on Phenacetin Abuse, edited by H. Haschek, pp. 11-23. Egermann, Vienna.

Gault, M. H., Rudwal, T. C., and Redmond, N. I. (1968). Analgesic habits of 500 veterans: incidence and complications of abuse. Canad. med. Ass. J., 98, 619-626.

Gilman, A. (1964). Analgesic nephrotoxicity. Amer. J. Med., 36, $167-$ 173.

Gilman, A. (1965). Pharmacologic problems in evaluation of the role of analgesics in production of renal disease. In Progress in Pyelonephritis, edited by E. H. Kass, pp. 353-354. Davis, Philadelphia.

Gloor, F. J. (1965). Some morphologic features of chronic interstitial nephritis (chronic pyelonephritis) in patients with analgesic abuse. In Progress in Pyelonephritis, edited by E. H. Kass, pp. 287-296. Davis, Philadelphia.

Grimlund, K. (1963). Phenacetin and renal damage at a Swedish factory. Acta. med. scand., Suppl. 405.

Grimlund, K. (1965). Fatal injuries from overdosage of phenacetin Proc. europ. Soc. Study of Drug Toxicity, 6, 90-96.

Grimlund, K. (1973). Phenacetin and renal damage. In Problems on Phenacetin Abuse, edited by H. Haschek, pp. 195-201. Egermann, Vienna.
Ham, K. N., and Tange, J. D. (1969). Some experimental observations relating to the pathogenesis of renal papillary necrosis. Ann. Med., 18, 199-208.

Harvald, B. (1963)Renal pa. pillary necrosis: a clinical survey $\overrightarrow{\overparen{~}} 66$ cases. Amer. J. Med., 35, 481-486.

Harvald, B., Valdorf-Hansen, F., and Neilsen, A. (1960). Effect of the kidney of drugs containing phenacetin. Lancet, 1, 303-308.

Høybe, G., and Nielsen, O. E. (1973). Renal pelvic carcinomes in phenacetin abusers. In Problems on Phenacetin Abuse, edited by H. Haschek, pp. 241-246. Egermann, Vienna.

Hultengren, N. (1961). Renal papillary necrosis: a clinical study $\overline{\bar{\alpha}} 103$

cases. Acta. chir. scand., Suppl. 277.
Jacobs, L. A., and Morris, J. G. (1962). Renal papillary necrosiஹand the abuse of phenacetin. Med. J. Aust., 49, 531-538.

Kennedy, A. (1965). Renal papillary necrosis and phenacetin $\tilde{N}_{\text {two }}$ further cases. Postgrad. med. J., 41, 498-500.

Kennedy, A., and Saluga, P. G. (1970). Urinary cytology in experimental toxic renal injury. Ann. rheum. Dis., 29, 546-552.

Kerr, D. (1970). Phenacetin nephropathy. Brit. med. J., 4, 363-3 $\overrightarrow{64}$.

Kincaid-Smith, P. (1967). Pathogenesis of the renal lesion assoc迢ted with the abuse of analgesics. Lancet, 1, 859-862.

Kincaid-Smith, P. (1969). Analgesic nephropathy: a common foth of renal disease in Australia. Med. J. Aust., 2, 1131-1135.

Kincaid-Smith, P. (1970). Analgesic nephropathy. Brit. med. J., 4,

Kincaid-Smith, P., Nanra, R. S., and Fairley, K. S. (1970). Analgesic nephropathy: a recoverable form of chronic renal failure्ड In Renal Infection and Renal Scarring, edited by P. Kincaid-Smith and K. F. Fairley, pp. 385-400. Mercedes, Melbourne.

Kincaid-Smith, P., Saker, B. M., and McKenzie, I. F. C. (1988a). Lesions in the vasa recta in experimental analgesic neptropathy. Lancet, $1,24$.

Kincaid-Smith, P., Saker, B. M., McKenzie, I. F. C., and Murfen, K. D. (1968b). Lesions in the blood supply of the papilla in experimental analgesic nephropathy. Med.J. Aust., 1, 2032206.

Kincaid-Smith, P., Whitworth, J., Fairley, K. F., and Nanra, B. S. (1973). Clinical course of analgesic nephropathy with failure. In Problems on Phenacetin Abuse, edited by H. Hasqek, pp. 157-184. Egermann, Vienna.

Koutsaimanis, K. G., and de Wardener, H. E. (1970). Phenacetin nephropathy with particular reference to the effect of ourgery. Brit. med. J., 4, 131-134.

Krikler, D. M. (1967). Paracetamol and the kidney. Brit. me.t. 2 , 615-616.

Lancet (1966). Renal disease and rheumatoid arthritis. (Exitgial) Lancet, 2, 1451-1452.

Lancet (1969). Analgesic abuse and tumours of the renal pofvis. Lancet, 2, 1233-1234. Lancet (1973). The wages of analgesics. (Editorial) Lancet, 2, $19084-$
1485 .

Lawrence, J. R., Disney, A. P. S., and Clarkson, A. R. (1973) The incidence, cost and some clinical features of analgesic nemropathy in Australia. In Problems on Phenacetin Abuse, editeg by H. Haschek, pp. 311-316. Egermann, Vienna.

Lawson, A. A. H., and McLean, N. (1966). Renal disease and $\overrightarrow{\tau_{r}}$ therapy in rheumatoid arthritis. Ann. rheum. Dis., 25, $44 \overline{9} 449$.

Lawson, D. H. (1973). Analgesic consumption and impaired renal function. J. chron. Dis., 26, 39-45.

Lindeneg, O., Fischer, S., Pedersen, J., and Nissen, N. I. (1959). Necrosis of the renal papillae and prolonged abuse of phignacetin. Acta. med. scand., 165, 321-328.

Lucke, V. M., Messervy, M., Lucke, J. N., and Hunt, A. C. (1968). Effects on the kidney of removal of the renal papilla.
Path., 86, 390-394.

Marrion, R. A., and Susmano, D. (1973). Phenacetin abuse causing bladder tumours. In Problems on Phenacetin Abuse, edite $\$$ H. Haschek, pp. 325-327. Egermann, Vienna.

Murray, R. M. (1972). Analgesic nephropathy: removal of phena歪tin from proprietary analgesics. Brit. med. J., 4, 131-132. Murray, R. M. (1973a). Survey of analgesic consumption. Lanc of 1 ,

Murray, R. M. (1973b). The origins of analgesic nephropath w In Problems on Phenacetin Abuse, edited by H. Haschek, pp. 2077292. Egermann, Vienna.

Murray, R. M. (1974). Analgesic abuse. J. hosp. Med., 2, 772-780

Murray, R. M., Lawson, D. H., and Linton, A. L. (1971). Analgesic nephropathy: clinical syndrome and prognosis. Brit. med. 1 ,

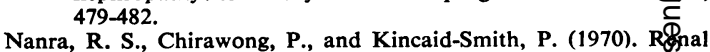
papillary necrosis in rats produced by aspirin. A.P.C. and other 
analgesics. In Renal Infection and Renal Scarring, edited by P. Kincaid Smith and K. F. Fairley, pp. 347-358. Mercedes, Melbourne.

Nanra, R. S., Chirawong, P., and Kincaid-Smith, P. (1973). Medullary ischaemia in experimental analgesic nephropathy-the pathogenesis of renal papillary necrosis. In Problems on Phenacetin Abuse, edited by H. Haschek, pp. 45-66. Egermann, Vienna.

Nanra, R. S., and Kincaid-Smith, P. (1970). Papillary necrosis in rats caused by aspirin and aspirin-containing mixtures. Brit. med.J., $3,559-561$.

Nanra, R. S., and Kincaid-Smith, P. (1973a). Experimental and clinical analgesic nephropathy with aspirin. In Problems on Phenacetin Abuse, edited by H. Haschek, pp. 89-114. Egermann, Vienna.

Nanra, R. S., and Kincaid-Smith, P. (1973b). Experimental renal papillary necrosis (RPN) with non-steroid anti-inflammatory analgesics. In Problems on Phenacetin Abuse, edited by $\mathrm{H}$. Haschek, pp. 67-88. Egermann, Vienna.

New Zealand Rheumatism Association Study (1974). Aspirin and the kidney. Brit. med. J., 1, 593-596.

Nordenfeldt, $O$. (1972). Deaths from renal failure in abusers of phenacetin-containing drugs. Acta med. scand., 191, 11-16.

Nordenfeldt, O., and Ringertz, N. (1961). Phenacetin takers dead with renal failure. Acta med. scand., 170, 385-402.

Olaffson, O., Gudmundsson, K. R., and Brekkan, Á. (1966). Migraine, gastritis and renal papillary necrosis. Acta med. scand., 179, 121-128.

Prescott, L. F. (1965). Effects of acetylsalicylic acid, phenacetin, paracetamol, and caffeine on renal tubular epithelium. Lancet, 2, 91-96.

Prescott, L. F. (1966). Analgesic abuse and renal disease in NorthEast Scotland. Lancet, 2, 1143-1145.

Prescott, L. F. (1969). Renal papillary necrosis and aspirin. Scot. med. J., 14, 82-85.

Prescott, L. F. (1970). Phenacetin nephropathy. Brit. med. J., 4, 493.

Prescott, L. F. (1970). Some observations on the nephrotoxicity of analgesics other than phenacetin. In Renal Infection and Renal Scarring, edited by P. Kincaid-Smith and K. F. Fairley, pp. 421435. Mercedes, Melbourne.
Robinson, M. J., Nichols, E. A., and Taitz, L. (1967). Nephrotoxic effect of acute sodium salicylate intoxication in the rat. Arch. Path., 84, 224-226.

Rubenstein, A. H., Abrahams, C., Stables, D. P., and Levin, N. W (1964). Acetophenitidin nephritis and papillary necrosis. Arch. intern. Med., 113, 378-394.

Saker, B. M., and Kincaid Smith, P. (1969). Papillary necrosis in experimental analgesic nephropathy. Brit. med.J., 1, 161-162.

Sanerkin, N. G. (1966). Chronic phenacetin nephropathy. Brit. J. Urol., 38, 361-370.

Scheidegger, S. (1958). Pathologisch-anatomischer Beitrag zur Frage der chronischen interstitiellen Nephritis in Anschluss an Abusus von phenacetinhaltingen Analgetica. Bull. Schweiz. Akad. med. Weiss., 14, 139-153.

Schourup, K. (1957). Necrosis of the renal papillae. Acta path. microbiol. scand., 41, 462-478.

Schreiner, G. E. (1963). The nephrotoxicity of analgesic abuse. Ann. intern. Med., 57, 1047-1052.

Scott, J. T., Denman, A. M., and Dorling, J. (1963). Renal irritation caused by salicylates. Lancet, 1, 344-348.

Sørensen, A. W. S. (1965). Effect of analgesics on renal function. A consecutive study by means of $24 \mathrm{hr}$ endogenous creatinine clearance. In Progress in Pyelonephritis, edited by E. H. Kass, pp. 312-324. Davis, Philadelphia.

Sørensen, A. W. S. (1966). Is the relationship between analgesics and renal disease coincedental and not causal? Nephron, 3, 366-376.

Spühler, O., and Zollinger, H. U. (1953). Die chronisch-interstitielle Nephritis. Z. klin. Med., 151, 1-50.

Swales, J. D., Funder, C. C., and Tange, J. D. (1973). Healed experimental renal papillary necrosis. J. Path., 109, 209-213.

Waters, W. E., Elwood, P. C., and Asscher, A. W. (1973). Community survey of analgesic consumption and kidney function in women. Lancet, 1, 341-344.

Welch, R. M., and Gillespie, D. D. (1973). Effect of cigarette smoking on the metabolism of phenacetin in man. In Problems of Phenacetin Abuse, edited by $\mathrm{H}$. Haschek, pp. 115-121. Egermann, Vienna.

Zetterlund, C. G. (1973). Phenacetin takers with urinary tract tumours. Hjorton's syndrome. In Problems of Phenacetin Abuse, edited by H. Haschek, pp. 247-255. Egermann, Vienna. 